\title{
Bio-Communication of Bacteria and their Evolutionary Roots in Natural Genome Editing Competences of Viruses
}

\author{
Günther Witzany*
}

Telos-Philosophische Praxis, Vogelsangstraße 18c, 5111-Buermoos, Austria

\begin{abstract}
Communicative competences and the use of a semiochemical vocabulary enable bacteria to develop, organise and coordinate rich social life with a great variety of behavioral patterns even in which they organise themselves like multicellular organisms. They have existed for almost four billion years and still survive, being part of the most dramatic changes in evolutionary history such as DNA invention, cellular life, invention of nearly all protein types, partial constitution of eukaryotic cells, vertical colonisation of all eukaryotes, high adaptability through horizontal gene transfer and cooperative multispecies colonisation of all ecological niches. Recent research demonstrates that these bacterial competences derive from the aptitude of viruses for natural genome editing.

In contrast to a book which would be the appropriate space to outline in depth all communicative pathways inherent in bacterial life in this current article I want to give an overview for a broader readership over the great variety of bacterial bio-communication: In a first step I describe how they interpret and coordinate, what semiochemical vocabulary they share and which goals they try to reach. In a second stage I describe transorganismic communication, i.e. the main categories of sign-mediated interactions between bacterial and non-bacterial organisms, and interorganismic communication, i.e. between bacteria of the same or related species. In a third stage I will focus on intraorganismic communication, i.e. the relationship between bacteria and their obligate settlers, i.e. viruses. We will see that bacteria are important hosts for multiviral colonisation and the virally-determined order of nucleic acid sequences, which has implications for our understanding of the evolutionary history of pre-cellular and cellular life.
\end{abstract}

Keywords: Social lifestyle, communication, sign-mediated coordination, biotic colonization matrix.

\section{INTRODUCTION}

Bacteria communicate and therefore are able to organize and coordinate their behavior similar to a multicellular organism $[1,2]$. We refer to communication processes as interactions mediated by signs. Signs are, in most cases, chemical molecules (in some cases also tactile interactions, i.e. specific behavior) which serve within and between prokaryotic organisms. Most bacteria are symbiotic organisms covering the whole range from mutualism to parasitism. They may be beneficial for their (eukaryotic) hosts and without them host survival would not function [3]. Others are neutral, i.e. they do not harm the host. Many of them also cause diseases, with sometimes epidemic characteristics and, often, lethal consequences.

Bacteria represent one of the main success stories of evolution. They originated at the early beginning of life similarly to archaea which represent a different organismic kingdom [4]. Bacteria are found in all ecological niches, and share a common flux of their gene pool with a high rate of gene order recombination for adaptational purposes of great diversity [5]. More than in any other organismic kingdom it is in common use to speak about the languages and even dialects of bacteria [6-11].

Quorum sensing is the term of description for signmediated interactions in which chemical molecules are pro-

*Address correspondence to this author at the Telos-Philosophische Praxis, Vogelsangstraße 18c, 5111-Buermoos, Austria; E-mail: witzany@sbg.at duced and secreted by bacteria [12-15]. They are recognized by the bacterial community dependent on a critical concentration and in a special ratio to the population density $[16,17]$. These molecules trigger the expression of a great variety of gene transcriptions. Many bacteria use multiple quorum sensing codes; each may be modulated by posttranscriptional or other regulatory engineering [18].

There are also communication processes between different species of bacteria (some term it bacterial Esperanto) and between bacteria and non-bacterial life such as eukaryotic hosts [19]. Beneath the semiochemicals (Gr.: Semeion = sign) necessary for developmental processes of great variety of bacterial communities such as division, sporulation and synthesis of secondary metabolites, there are physical contact-mediated behavioral patterns which are important in biofilm organization [20-23]. Also, abiotic influences serve as signs which indicate specific nutrients or other environmental circumstances such as hydro- or heatdynamic changes.

As communities of bacteria species, which are able to coordinate their behavior and have advantages over single bacteria organisms, are much more common, it is not surprising that the evolutionary drive went into rising communicative complexity [24]. We should not forget that in comparison to the first two billion years of life on earth with closed prokaryotic symbiology the rise and growth of the multicellular eukaryotes (animals, fungi, plants) was a crucial advantage for bacterial lifestyle to colonize vertical hosts with their great spatial and motility resources. 
We can differentiate three classes of molecules which serve as signs for different purposes, i.e. sign-mediated interactions within the organism to coordinate gene expressions to generate adequate response behavior, sign-mediated interactions between the same or related and different species. With a limited number of molecules and a limited number of combinatorial rules they generate quite different interactions for different purposes all mediated by signs. As in every sign-mediated interaction sign users share a common set of syntactic rules, i.e. how signs may be combined; of pragmatic rules which determine a great variety of interactional contexts, e.g. development, growth, mating, virulence, attack and defence. The situational context of these complex interactional processes determines the meaning of signs, i.e. their semantics. Independent of organismic complexity the complementarity of these three levels of semiotic rules can be identified, in principle, in every sign-mediated interaction within and between organisms [25,26]. This leads to the generation of intra- and intercellular processes which enable bacterial communities to generate memory which may be inheritable but can alter epigenetically, i.e. different reading/meaning patterns of the same genetic data set with differences at the phenotypic level without altering the genetic data set.

\section{BIOCOMMUNICATION: RULE-GOVERNED, SIGN-MEDIATED INTERACTIONS}

The link between linguistics and genetics has been obvious since the detection of the universal grammar and the structural code of DNA [27,28]. Chomsky's meaningindependent syntax approach lead to the broad acceptance and usage of bioinformatic methods and systems biology. Researchers in bacteria communication like Ben Jacob [11] suggested with good reason that this approach reduces linguistic competences found in bacterial communication and has to be satisfied by both semantic aspects, i.e. the contextdependent meaning of molecules which act as signs, and pragmatic aspects, which focus on the variety and differences of the behavioral patterns in common-goal coordination, shared knowledge, memory and mutual intentions. Apart from that, it is coherent with the presupposition by Charles Morris of any non-reductionistic analysis of language-like structures, the complementarity of syntax, semantics and pragmatics [29].

We use the term "sign" because of its multilevel appropriateness, rather than "signal", which is a term from information theory and is closely connected to cause and effect mechanisms with no dependence on interpretation processes. According to Charles Sanders Peirce, three types of sign can be distinguished: index, icon, and symbol. Indices are phenomena that serve as a sign for an interpreting organism, e.g. smoke can serve as an index for animals and cause them to keep away because of the dangerous effects of fire. Icons are signs that are associated directly with their meaning because of their analog character, e.g. if worker bees fly through the flying swarm in one direction this is an iconic sign about the direction in which nutrients are available. Symbols are conventional signs within species-specific populations that do not indicate directly what their meaning is, e.g. the dances of bees in the northern hemisphere transport a message about the location of nutrients according to a special direction in relation to the sun and according to the distance from the nutrients. Because these symbols are expressed by active motility we can see that gestures or behavioural patterns may also serve as signs. Their meaning often depends on the situational and cultural context of the members of a population that use these signs, as demonstrated by the Nobel laureate Karl von Frisch. He proved that certain dialects of different bee populations using the same signs have different meanings. As outlined in great detail "sign" is therefore the better designation than "signal" for information-bearing molecules used in the bio-communicative processes in bacteria, animals, fungi and plants [26-29].

One of the best investigated biocommunication processes between bacteria is the sign-mediated coordination called biofilm-organisation: Bacteria have profound effects on human health, agriculture, industry and other ecospheres. Therefore they target the multiple drugs which fight them [30]. They develop drug resistance by coordination of special defensive behavior. Biofilm organization is a special kind of coordination with a high density of physical contact and contact-specific signs [2]. If bacteria realize a critical mass via quorum sensing they organize a high density of communal body by moving their flagellas which may resist even strong antibiotics [31]. Biofilms are constructed on abiotic surfaces, e.g. on stones in rivers and other aqueous surfaces, as well as biotic ones, e.g. in the respiratory track of animals. Each human who had a strong cough remembers like persistent the mucus in the bronchial tube remained.

Nutrient availability also regulates the structure of biofilm organization [32] as hydrodynamic forces [33]. Interestingly, it has been found that biofilm organization is linked with coordinated DNA release which is integrated in the biofilm [34].

\section{SEMIOCHEMICAL VOCABULARY AND COM- MUNICATIVE GOALS}

The sum of the semiochemical vocabulary each used by different bacteria is of great variety, especially because some sign-molecules are multiple reusable components [35]. Acyl homoserine lactones (AHLs) and linear oligopeptides are used as signs in diverse processes. Cyclized oligopeptides function as virulence genes. g-Butryolactones (GBLs) are used as antibiotics and in sporulation processes. Furanosyl diester (AI-2) is used in diverse processes [36] and in luminescence. cis-11-Methyl-2-dodecenoic acid (DSF) serves in virulence and pigmentation. 4-Hydroxy-2-alkyl quinolines (PQS, HAQs) are important in whole regulation processes and for virulence as are palmic acid methyl esters (PAME). Putrescine is important in swarming motility like biofilm organization. "A-signal" is used in early developmental processes and aggregation. "C-signal" is a cell surfaceassociated protein and serves to coordinate motility and the developmental process of building a fruiting body. Cyclic dipeptide is a secondary metabolite [37,38]. Gram-negative bacteria use homoserine lactones (LuxR/LuxI) as signs in communication processes [7, 39], whereas Gram-positive bacteria use oligopeptides in quorum sensing communication. As in all organisms non-coding RNAs are important in higher order regulatory pathways. Small RNAs and microRNAs are used by bacteria to regulate special genetic expression patterns which play an important role as appropriate response behavior to stress or nutrient availability [40,41], e.g. in controlling the quorum sensing pathways [42]. 


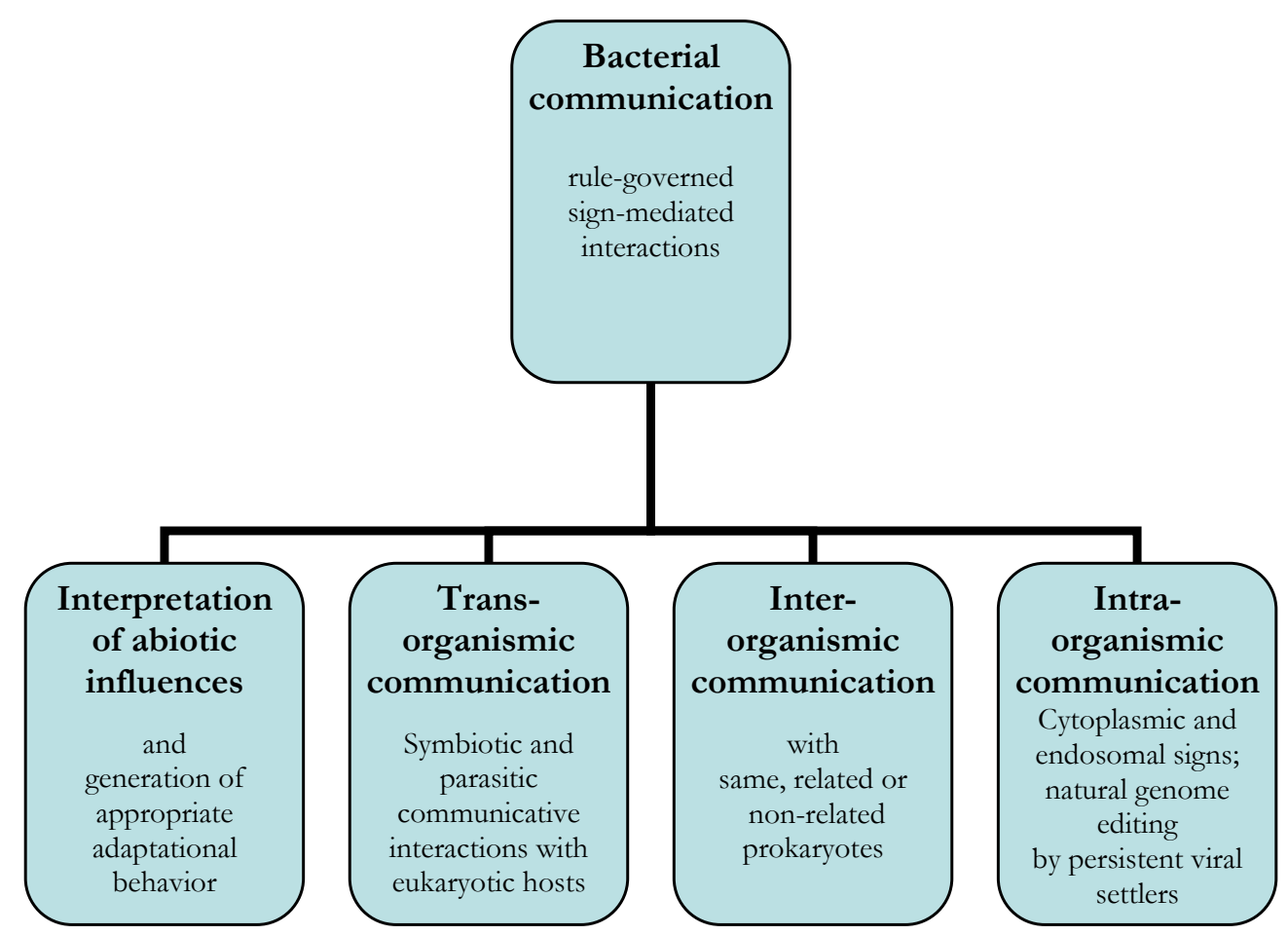

Fig. (1). Levels of communicative competences of bacteria.

At present, three kinds of communicative goals are distinguished: (A) reciprocal communication, active signmediated interactions which are beneficial for both interacting parts; (B) messages which are produced as response on a triggering event which may be an indicator for a receiver which was not specially targeted by the producer. A coincidental event which is neutral - except for the energy costs of production - to the producer but beneficial for the receiver; (C) signs to manipulate the receiver, i.e. to cause a response behavior which is one-sided - beneficial to the producer and harmful to the receiver [38], often in that they behave against their normal goals [43].

The three classes of trans-, inter- and intraorganismic communication enable bacteria to generate and coordinate different behavioral patterns: self and non-self identification, i.e. recognition of other colonies and measurement of their size, pheromone-based courtship for mating, alteration of colony structure in formatting of fruiting bodies, initiation of developmental and growth processes, e.g. sporulation.

In receiving signs from same or related species or nonbacterial organisms the semiochemical molecules bind to specialized sensor proteins which function as receptors. They transmit the message to an intracellular regulator $[38,44]$, i.e. the sign-molecule transits the cell membrane through diffusion or by specific transport pathways. Inside the cell the sign-molecule, in most cases, binds to a cytoplasmic target protein. It may be that a diffusible molecule is chemically engineered to an active sign after entering the target cell [38]. Organization of cellular production of response molecules leads to sign-dependent transcription control of DNA.

Bacteria have to distinguish between species-specific signs and signs which are able to modulate behaviors interspecifically [8]. With these communicative competences they are able to coordinate species-specific behavourial pat- terns as well as to coordinate behaviors between diverse species.

\section{TRANSORGANISMIC BIOCOMMUNICATION OF BACTERIA}

Starting with beneficial symbioses between bacteria and plants we refer to the complex communication networks between soil bacteria, mychorrizal fungi and plant roots [4547]. Mychorrizal fungi secret molecules in the surrounding environment which serve as nutrients for soil bacteria and trigger their activation to degrade special nutrients which are then available for mychorrizal fungi. Their hyphal growth serves as the developmental and growth area of plant roots, themselves being dependent on nutrients which are prepared by the mychorrizal fungi. Plant roots can also mimic bacterial sign-molecules, either to trigger bacterial production of special molecules or to disturb bacterial communication pathways $[40,42,15]$.

Rhizobia bacteria are integrated into plant cells by phagocytosis when they interact symbiotically with the plant roots [48]. In other cases where rhizobia fail to fix nitrogen inside the root nodules because they are being deceptive, plants are sanctioning these rhizobia [49] and prevent their spread in order to stabilize mutualistic symbioses with bacterial colonies [43]. Root exudates of different kinds regulate plant and microbial communities in the rhizosphere. This is necessary to stabilize equilibrium and inhibit the continuity of attacks by pathogenic bacteria in the soil $[45,46]$. The full range of trans-specific communication processes between bacteria and plant roots are important for developmental and growth processes in the entire plant kingdom [13,50].

Chemical molecules which serve as signs in intercellular communication processes of bacteria are similar to pheromones in social insects and animals. This may be an indica- 
tor of evolutionary lineages that evolved in the bacterial 'chatter' [51].

Marine eukaryotes are able to mimic bacterial quorum sensing to inhibit bacterial successful communication [52]. Interbacterial communication uses hormone-like signs to sense specific host locations such as intestinal habitat. In this specialized ecosphere a bacteria-host communication occurs which means the host cells and bacterial cells share a common meaning function for the same sign-molecules [53].

Living as endosymbionts as potential candidates for symbiogenesis [54-57] as documented in the origin of eukaryotic endosomes like mitochondria, indicates the important role of bacteria for the entire history of evolution [58]. The interactions may be pericellular colonization events but also an intracellular lifestyle. These different symbiotic interactions range from acquisition of novel genetic material to reduction in size and content connected with gene loss [59]. Successful living processes of higher eukaryotes would not be viable without beneficial symbiosis with bacteria. The cell mass of an adult human assembles $20 \%$ of human origin and up to $80 \%$ of exogenic settlers [60], most of them bacteria.

\section{INTERORGANISMIC INTERACTIONS - SOCIOBACTERIAL COMMUNICATION}

For a long time it was assumed that bacteria live predominantly as monads. However, it has been recognized that this is a very rare exception $[61,62]$. Bacterial colonies live, in almost all cases, not alone but in coexistence with other bacterial species self-coordinated by a diversity of signmediated interactions $[63,64,1]$. Bacteria use intraspecific and interspecific sign-molecules in all ecological in vivo situations [43]. This also implies a broad variety of conflicts within and between species [65]. The mutual, neutral and manipulative aims of communication processes are special kinds of response behavior to certain degrees of beneficial up to conflictual relationships [43].

Dependent on the availability of nutrients, some bacteria suppress normal cell development which leads to the development of a different cell type which is better suited for adequate response behavior for this situational context. It means that different environmental conditions can lead to different gene expressions within the same genomic data set. It has been shown that if the same colony is exposed several times to these changing contexts they react more immediately. This indicates that bacterial communities are able to develop collective memory and learn from the experience [11,64]. This functions similar to neuronal networks in higher eukaryotes. In the case of changing environmental conditions, the suppression of cell division may lead to cell elongation which enables cell colonies to change the modus of motility. This is an important feature of socio-bacterial behavior, e.g. swarming coordination and organization for surface colonization $[37,66]$.

Some authors have documented altruistic strategies in mixed colony formations which seems to be an advantage to the mixing among microcolonies. Altruistic behavioral strategies enable strengthened self-identity and a sustainable equilibrium in multilevel colonized ecological niches [67, 68].
Interestingly, bacteria use a common contextual interpretation of incoming signs by each member of the colony. The response behavior is appropriate to the majority vote [11] of the context-dependent decision. The identification of nonself species is a competence which is possible through species-specific and group-specific quorum sensing and is coherent with the assumption that smaller groups of the same bacterial species are able to built types of quorum-sensing 'dialects'. These are important in the high density of coexistent bacterial life habitats to prevent confusion and enable more complex coordination [69]. Interestingly, the prokaryotic cell-cell communication has structural analogues to cross-kingdom signs used in biocommunicative processes between bacteria and fungi [70].

Some bacterial species decide, in special cases, to form fruiting bodies of different types and shapes for sporulation. This enables these bacterial communities to more efficiently disseminate the spores. The fruiting body building is governed by context-specific rules with different roles for different sub-groups of bacterial communities for coordination [71]. Some have to serve for motility to density, followed by direction decision and decision of cell types, cell growth and developmental stages in all the different steps until the fruiting body is ready for the sporulation event. Without communicative hierarchical organization this would not be possible. If communication is disturbed body building is not assured, so bacterial communities have developed special strategies to single out so-called 'cheaters' [65,11], which do not follow the rules for coordinating this special behavior.

One of the most interesting and best investigated phenomena of bacterial communication is the symbiology of multiple colonies coexistent in the human oral cavity [7274]. Bacteria on human teeth and oral mucosa establish a homeostasis of pathogenic and mutualistic bacteria by a complex system of sign-mediated interactions both speciesspecific and trans-specific. The dental plaque in the oral cavity of humans is a unique habitat which is not found in any other species [75]. The homeostasis is not static but is the result of a dynamic relationship between different speciescolonies dependent on intervals of daily hygiene. The interacting species number approximately 500 different species [76-78].

Each member of these communities must be capable of self and non-self distinction, and be able to distinguish between species-specific signs and trans-specific signs or even 'noise' (no biotic icon or symbol, no abiotic index). As a community they must be able to measure their own colony size and the size of the other colonies and distinguish molecules that have the same chemical structure but are not part of a biotic message. Special communication patterns with detailed hierarchical steps of sign-molecule production and transmission include (i) metabolite exchange, (ii) cell-cell recognition, (iii) genetic exchange, (iv) host sign recognition and sign recognition of same or related species. Owing to the high number of competing and cooperating species there is a special short- and long-term community architecture established. If the communication on the intra-, inter- and transorganismic level is successful, i.e. the sign transmission and reception enables colonies to live in a dynamic homeostasis, then the human oral cavity will avoid cavity diseases [72,73]. 


\section{INTRAORGANISMIC COMMUNICATION: SIGN- MEDIATED INTERACTIONS WITHIN BACTERIA}

After the description of transorganismic communication processes (i) between bacteria and non-bacterial organisms and (ii) interorganismic communication processes among bacterial species, let us have a look at intraorganismic communication processes (iii) within bacterial cells. This includes generation, modifications, regulation of prokaryotic gene word order and its evolutionary roots.

Interestingly, prokaryotic gene order is not as conserved as the sequences which code for proteins. Only some higher order regulations (operons) that code for physically interacting proteins are found in almost all bacterial (and archaeal) genomes. Recent research indicates high dynamics of new gene orders as documented in the horizontal gene transfer events with their intensive intragenomic recombination $[79,80]$. This exchange of whole genes or gene-blocks enables bacterial lifestyles to combine several bacterial competences, i.e. phenotypes. The transformation process includes the release of naked DNA, followed by the uptake and recombination, i.e. the integration, with 17 steps identified to date exemplified excellently by Thomas and Nielsen [81]. Thus we can recognize the outcomes of a diversity of mobile DNA contents [82], not a mass of individualized genetic texts, but a bacterial gene pool as a text repertoire which is available for each individual bacteria and the resource for bacterial genome innovation and evolution [83]. Horizontal gene transfer is a main resource for integrating newly evolved genes into existing genomes and does not need the slow steps of chance mutations to alter the genomes but accelerated genome innovations in both bacteria and archaea [84-86]. Important in this context of genomic innovation is not the sequence acquisition alone but also the contextualization [87], it means also their loss [88]. It seems now that the phylogeny of microbial species is not a tree of life, but an evolutionary network or a ring of life, mediated by genetic exchange, i.e. acquisition and loss of genetic data sets $[89,90]$.

\subsection{Intracellular Communication}

Sign-dependent transcription regulation of the DNA serves for a great variety of response behavior. One of the most interesting phenomena is the fact that in the first two billion years of life on planet earth the immense density of bacterial life has not been an event of the mass of individual organisms but their commonly shared gene pool which was in constant flux, as we now know, through investigations on horizontal gene transfer. It means that the evolution of bacteria was not a random event of chance mutations and their selection but transfer of whole genes and gene-blocks representing real phenotypes that were transferred. This leads to different combinatorial patterns of genetic encoded phenotypes and the rise of bacterial diversity. It also enables bacterial pathogens to optimize their disease-causing coordination and is therefore targeted to special kinds of drug developments for medical purposes [91]. New empirical data seem to suggest that the phenomenon of horizontal gene transfer is driven by viral competences inherent in bacterial settlers such as phages, plasmids, retroplasmids and transposons [92]. This means, to understand intraorganismic communication of bacteria we have to look at the roles of viral settlers in bacteria as outlined in the following chapters.
For a long time it has been proposed that tubulin plays an important role in cytoskeletal functions of eukaryotes whereas prokaryotes lack this system. Recent research has shown that tubulin is a very ancient system for genetic data set segregation also in bacteria which plays important roles in filament formation, movement and orientation [93-97].

\subsection{Bacterial Evolution and the Agents of Natural Ge- nome Editing}

To elucidate communicative competences of bacteria we also have to look at the roles of viruses and their relationship to bacteria. Viruses have long been accepted only as disease causing, epidemic phenomena with lytic and therefore extremely dangerous consequences for infected organisms. However, new research has corrected this picture. Viruses are part of the living world, in most cases integrated in the cytoplasm or the nucleoplasma of cells without harming the host. Viruses are on their way to representing the best examples of symbiotic relationships, because there is no living being since the start of life that has not been colonised by them, in most often cases in the form of multiple colonisations [98]. The longest period of these symbiotic relationships during evolutionary history share viruses, archaea and bacteria. As viruses are extremely biosphere specific, i.e. they adapt to special host tissues, the identification of various forms of, e.g. bacteria is to identify primarily the viruses that colonise them. This is also the concept of 'bacteriophages', in that bacteria are identified best by identifying the viruses that are associated with them [92]. Host identification in this way is a special method called phage typing.

\subsubsection{Lytic Versus Persistent Viral Life-Strategies}

As mentioned in recent years, the lytic consequences of viral infection are a special case if viruses are not able to develop a sessile lifestyle without harming the host. In most cases viruses living within organisms help to ward off competing parasites from the host and becoming part of its evolutionary history. Persistent, non-lytic viruses are decisive for species diversity and host genome editing. Nearly all natural genome editing competences represented in the conservation of expression, transcription, translation and recombination with all their detailed steps seem to derive from viral aptitudes. Even the DNA replication pathways, after a period of early RNA influence [99-101], seems to be a special viral strategy for the conservation of coded phenotypes by warding off RNA parasites [102,92].

Since observations have become more evident that viruses are able to integrate genetic material into the host genome, it has become clear that some viruses have lytic infection lifestyles but others also endosymbiotic and even symbiogenetic lifestyles. They bestow phenotypic capabilities on the host which non-infected hosts from the same species do not possess. As endosymbiotic viruses which are dependent on the host's replication they are part of the host history in that they are inheritable and part of the genomic identity of the host as documented in some several 10,000 infection events in the human genome by endogenous retroviruses [103].

The two viral lifestyles are not in strict opposition but, in most cases, are part of a symbiotic process. It starts with an infection by a virus. In the infected host it arrives at an 
equilibrial status where the immune system does not eliminate the virus but controls its replication without fatal consequences for the host organism. The persistent status lasts during most phases of the host's life, but may return to the lytic lifestyle if the host-immune system is under stress [104]. Most often the integration occurs by mutual neutralisation of toxic capabilities by an antitoxin of a competing genetic settler [105]. The whole range of toxin/antitoxin addiction modules we can find throughout all genetic contents in living nature most likely is of viral origin [92]. Therefore the persistence is sometimes called temperate lifestyle. A good example is the persistent virus in all Symbiodinium species being the essential endosymbiotic partner for coral animals. Coral bleaching as a worldwide phenomenon of coral disease is the consequence of dying of the coral endosymbiont because of global (water) warming. As we know now, death occurs because the persistent viruses of Symbiodinium become lytic as a reaction to the changing water temperature [92].

Also bacteria may be infected by viruses without being harmed. If infected bacteria meet non-infected bacteria it may be that the non-infected acquires lysis; the lysogenic strain does not lyse itself, but is lethal to the non-infected one. The colonized bacteria has a virus-derived molecular genetic identity which has an advantage against the noninfected one through an acquired ability. This lysogenic bacteria, termed prophage, has an immunity function for the bacteria which the non-infected bacteria lack. Prophage is a virus that is integrated into the bacterial host genome. Both the acute lytic phages and the persistent prophages are highly abundant in oceans and in the soil and seem to be the most dynamic life form on the entire planet. Some viruses are not integrated in the host genome but persist as plasmids and replicate independently from the host genome [92].

When we speak about the relationship of bacteria and viruses in most cases we speak about phage ecology. Most prokaryotic viruses are double-stranded DNA viruses with either linear or circular genome morphology and are packaged in an icosahedral capsid. Whereas acute viruses in most cases code for their own replication, recombination and repair proteins, the persistent phages lack such genes and use the host-cellular replication. This involves a totally different gene word order [92] in acute lytic and in persistent phages. This is documented in the very different nucleotide words (di-, tri- and tetranucleotides). Nucleotide word frequences of acute phages are very dissimilar to those of their hosts while persistent or temperate phages share nucleotide word frequences with the host. This means the molecular syntax from acute and persistent phages is constructed totally differently according to the different strategies. Different life strategies with different behavioral pathways need a completely different semantic content in the genome expressed in a different syntactic arrangement of nucleotides [98].

As the bacterial cell walls differ substantially between different types of bacteria a different behavior is necessary for viruses for recognition, attachment and penetration. Owing to these diverse barriers of the bacterial cell walls, the prokaryotic viruses do not enter the host cells physically but attach to the cell surface and inject their genomes through contractile tails or pilot proteins. Also, the progeny of the virus has to deal with this barrier [92].
Bacterial DNA does not have highly stable structures as do eukaryotes and can interact with the cellular replication and transcription. In most cases it is circular with a unique origin of replication system. In contrast to that viral doublestranded DNA is a linear DNA with integrated short terminal repeats. Since bacterial viruses do not use a transport technique as they need in eukaryotes to be transported out of the nucleus, bacterial viruses differ a great deal from eukaryotic viruses.

All bacteria have a restriction/modification system which is a connected form of two viral competences. Only the descendants of mitochondria lack this system which causes them not to be exposed to viral selection. It may be that they have transposed their ability to the eukaryotic nucleus which cares in a more efficient way for cell immunity [92].

\subsubsection{Bacteria as Biotic Matrix for Natural Genome Edit- ing}

Horizontal gene transfer between bacteria as being responsible for genetic plasticity in prokaryotes may be a capability which is acquired by viral infections. Then, viral genetic inventions are transferred to bacteria via persistent lifestyles of viruses and are not an exchange phenomenon performed by bacteria.

As new research indicates the agents of horizontal gene transfer are plasmids, retroplasmids, bacteriophages and transposons. They effect DNA movements and act in all prokaryotes. DNA movement is achieved through transformation, conjugation and transduction. Transformation is the transfer of DNA between related bacteria mediated by encoded proteins. Conjugation is performed by conjugative plasmids which are independently replicating genetic elements. These elements code for proteins which facilitate their own transfer [106]. Transduction is a DNA transfer mediated by phages which can package host DNA in their capsid and inject it into a new host followed by integration into the host genome [107]. Phages, plasmids, retroplasmids and transposons therefore played a crucial role in bacteria evolution [108]. Bacteria are the most genetically adaptable organisms with enormous capabilities to react appropriately to extreme changes of their ecological habitats. This does not stem from their high reproductive rates but from their great ability to acquire DNA segments by plasmids, bacteriophages and transposons which transport complete and complex sets of genes from external sources [66].

When we consider the age of the ocean and the dense abundance of bacterial and viral life in it, then we can say that the possibility of genetic arrangements, rearrangements and exchange does not need long time periods to create the basics of the complexity of life, because the exchange rate is of astronomical order. If we imagine that $1 \mathrm{ml}$ of seawater contains one million bacteria and ten times more viral sequences it can be determined that $10^{31}$ bacteriophages infect $10^{24}$ bacteria per second [91]. Since the beginning of life this behavioral pattern has been an ongoing process. The enormous viral genetic diversity in the ocean seems to have established pathways for the integration of complete and complex genetic data sets into host genomes, e.g. acquisition of complex new phenotypes via a prophage can include the acquisition of more than 100 new genes in a single genome editing event [109]. 
Owing to the virus-induced genomic plasticity of bacteria they are an ideal global biotic matrix to evolve and develop varieties in genome editing, i.e. competent content arrangement of bacterial gene word order coherent with its regulation network. Bacteria are the smallest living organisms with relatively simple genomic structures where the competitive situation between an abundance of viral infective elements leads to the adaptation of lytic viruses to temperate viruses integrated as plasmids in cytoplasma and even persistent viruses integrated in the host genome. The viral competences can develop in this dense global bacterial habitat as the bacterial species due to their immense genetic flux between viral colonization events and immunity reactions such as restriction/modification [110,111].

The highly conserved genome edited functions such as replication, transcription, translation, recombination and all the substeps evolved primarily in the competitive situation between viral competences to colonize a host and to ward off competing parasites. This includes that biotic self and nonself recognition functions as we know it from diverse immunity systems are also of viral origin, i.e. the integration and all genetic/genomic modification steps that what we call natural genome editing are of viral origin. Therefore the immense importance of horizontal gene transfer for bacterial species evolution, diversity and competences is derived from viral genome editing competences and is, in most cases, infection induced by persistent non-lytic viruses [112,106]. As phylogenetic analyses demonstrate, the main protein enzymes for natural genome editing are viral inventions and not of cellular origin $[92,103]$. Also, the origin of eukaryotic nucleus was thought to be an ancient prokaryote but phylogenetic analyses show that its ancestor seem to be a large DNA virus [113-115]. Interestingly, the early genetic invention of capsid proteins detected in viruses infecting archaea seems also to be of viral origin and of common ancestry to eukaryotic and bacterial viruses [116-118].

\subsubsection{Bacteria Successfully Escaped from the Selective Pressure of the Early RNA World}

For a long time bacteria have been considered to be the forerunners of the eukaryotic superkingdom. Although the evolution of eukaryotes did not occur by random mutations of bacterial genomes but by integration and natural genetic engineering of former free-living prokaryotes [25], the key features of the eukaryotic nucleus have less in common with prokaryotic competences than with some double-stranded (ds)DNA viruses [98]. The textbook conviction of the early $21^{\text {st }}$ century on the evolutionary history of eukaryotes was that an ancient prokaryotic cell was colonised by a large dsDNA virus and afterwards by mitochondria-like and chloroplast-like bacteria which together built the first eukaryotic cell. This scenario makes sense from a cytological perspective, because prokaryotes are much simpler than eukaryotes. From the perspective of an early RNA world, however, this view changes.

A "virus-first"-scenario from biocommunicative perspective would look like this: At the beginning there were singlestranded unencapsulated RNA molecules with an aptitude to replicate themselves, which through both their coding and catalytic capabilities, built complex structures with multiple functions to form dsRNA genomes in a pre-DNA world [119]. If we term these pre-cellular RNA replicators as vi- ruses then ssRNA viruses evolved into dsRNA viruses. Via a reverse transcriptase function present in a RNA-dependent RNA-polymerase [120,121], these dsRNA viruses evolved later on into dsDNA viruses. Now the stable DNA of dsDNA viruses was advantageous for colonising the unstable nucleotide word order in the genomic contents of RNA viruses. In parallel, DNA of dsDNA viruses served as an appropriate habitat for infection events by retroid agents. By holding these colonisation interrelations in a non-lytic but persistent inheritable status, infection forced the colonised RNA viruses to establish a bi-layered cell membrane and to encapsulate the genome in a porous nuclear envelope. Currently this could be a coherent explanation for the three remaining cellular DNA replication competences, i.e., the beginning of cellular life would have been entangled completely with three population-like genetic lineages, similar to those suggested by Forterre and co-authors [122].

These steps from ssRNA to dsRNA and from dsRNA to DNA are hallmarks in the evolution of life from a prebiotic assembly of ribonucleotides into a functional agent with simple nucleotide grammar-editing abilities. However, this agent also had to include a self/non-self differentiation capability, being able to ward off competing agents through the first immune function similar to RNAi. In parallel this would have been an advantage for colonising RNA replicators that lacked this capability.

\subsubsection{Communal Evolution: From LUCA to LUCAs}

For a long time the first living cell has been imagined as a single agent, known as the last universal common ancestor (LUCA), which was the forerunner of all later evolutionary steps into the three domains of life. According to our biocommunicative scenario the pre-cellular agents that were competent in RNA-, DNA- and Retro-editing were population-like nucleic acid sequence-editing species with commonly shared group behavior (self/non-self identification), group identity, and group interpretation.

This would be coherent with linguistic research, which states that (i) every biotic agent that is competent to use and interpret linguistic-like signs needs a community (either as a gene-pool and/or interactional) with which it shares these capabilities, i.e. linguistic competences cannot emerge in isolated individuals [123] and (ii) if linguistic-like competence for editing of nucleic acid languages evolved, the capability to generate not only simple but also complex new sequences would grow exponentially and not arithmetically.

This could explain both the great diversity of singlecelled life soon after pre-cellular life-processes started and the common feature of evolutionary processes, i.e. the invention of new genetic data as whole sequences, genes or geneblocks. When the pre-cellular consortium of three different viral - or even subviral - lineages developed a common genetic code, which further on served as a stable DNA storage medium for the evolution of the three cellular domains, I suggest we should be talking about the last universal common ancestors (LUCAs), because one single ancestor couldn't evolve both (i) sequence editing competences (ii) a competence for sign-mediated interaction necessary for coordination of common behavior (group identity) and self/non-self identification [124,125]. 


\subsubsection{Old but Good: Current Competences from an An- cient World}

Interestingly, even today we can look at relics of precellular evolution in both RNA viruses and viroids. Viroids and their monophyletic sister group, satellite RNAs, are short circular ssRNAs, viroids being unencapsulated whereas satellite RNAs are encapsulated. We know that viroids have extreme plasticity in their nucleotide sequences, being the most rapidly evolving biological agents [126-129]. Important features of small RNAs such as RNA silencing seem to derive from viroid competences [130-132]. The most conserved competences of RNA viruses and viroids are RNA stem-loop structures, which play important roles in priming and replication, with an inherent self/non-self differentiation in that they determine RNA replication to viral and not to host RNA molecules [92].

We now can imagine eukarya-like dsDNA viruses with the ribozymatic function of endonucleases competent in RNA-splicing, excision of introns out of tRNAs [133], integration of retroid DNA [134] and its key features, a double membrane, linear chromosomes with telomere ends, intronic elements with regulatory functions [135], segregation of transcription and translation and the subviral competences which we find in the ribonucleoprotein structures of premRNA, pre-tRNA and pre-rRNA, all processed by small nucleolar (sno)RNAs and small nuclear (sn)RNAs. As we know today, the precursor RNAs are a highly sophisticated network of regulatory agents, each of them with a separate RNA processing pathway. Although in prokaryotes we do not find linear chromosomes with telomere repeats, the ancient nuclear pore complex [136] or the highly mobile genetic settlers inherent in introns that are competent in RNAsplicing, we do find them in eubacterial and archaeal phages.

In addition, prokaryotes share a circular genome with nearly intron-free genetic syntax, whereas the seemingly evolutionarily later eukaryotes have linear chromosomes with telomere repeats to protect their ends against genetic invaders and genomes that are highly colonised by virusderived agents such as transposons, retroposons and related genetic settlers.

Although the "error-prone" coding-fidelity of the RNA world at the beginning was an advantage for fast adaptation, the evolutionary target evolved into both the relatively stable DNA configuration (via the reverse transcriptase competence - the only encoded function common to all retroelements) and the resistant protein world necessary in the high temperature environments of archaeal populations. Prokaryotes lack the key features of the early RNA world and therefore they would appear to be specialised fast-adapting singlecelled organisms that used the advantages of the stable DNA storage medium to code for highly temperature resistant protein structures to protect this storage medium.

Although accelerated ssRNA processing of mRNA, tRNA and rRNAs in linear RNA genomes built core competences for natural genome editing in the early RNA world, those ssRNAs without cellular habitats are extremely thermolabile and could not survive in high temperature environments [137]. The lack of RNA correction and repair and the high rate of replication combined with innovation allowed a rate of recombination events $1-10 \times 10^{6}$ times faster than in
DNA genomes [134]. RNA-based life-forms could evolve millions of times faster than DNA-based systems. This was an advantage for the exploration and invention of new sequence space, i.e. new genomic content with phenotypic competences and functions. In contrast, circular genomes with few higher order regulatory elements (represented by a diversity of genetic parasites present in intron-like genomic habitats) had more advantages in a high temperature environment and could adapt faster because of their ability to exchange selected phenotypes within and between proteincoding data-sets, as happens in horizontal gene transfer. So RNA cultures with eukaryote-like RNA-processing seem to predate the evolution of prokaryotes, which adapted to fastchanging environmental conditions by reducing their genomic content to a DNA with nearly analog (intron-free) protein-coding data-sets. This could be the evolutionary pathway from ribozymes of the early RNA world to ribonucleoproteins via low complexity RNA-chaperones to a DNAprotein-based life [126,137-139]. That eukarya-like genomes predated prokaryotic genomes is consistent with the existence of telomeres and telomere-like functions in ancient dsDNA viruses that seem to be the ancestors of the eukaryotic nucleus and are not part of prokaryotic genomes, although some are found in persistent bacteriophages [140].

Multiple small regulatory RNAs also play important roles in the bacterial expression of target genes at the posttranscriptional level. They are immediately available after being transcribed from the non-protein-coding sections of bacterial genomes, unlike protein enzymes which must be translated as well [141-145]. From the perspective of evolutionary history, bacteria seemed to reduce the predated RNAbased metabolism of early eukarya-like genetic content arrangements to become specialised in highly-selective environmental conditions such as high temperature and/or fastchanging nutrient availability, dependent on nearly intronfree DNA-protein metabolism [146], and containing circular genomes with only one starting-point for replication. As intron-rich linear chromosomes are the preferred habitat for persistent retroviral infections, and because of their important role in host-genetic content (re)arrangements, the invention of bacterial circular genomes must have had an effective immune function against retroviral infections. The result was the evolution of organisms that successfully escaped the high selective pressures of the early RNA world.

\section{SUMMARY}

For a long time bacteria have been assumed to be the most primitive organisms and consequently have been investigated as single-cell individuals determined by mechanistic input-output reactions. Now this picture has changed radically. Today we know that bacteria are part of a bacterial community that interacts in a highly sophisticated manner. The medium of every bacterial coordination is communication, i.e. sign-mediated interaction. A wide range of chemical molecules serve as signs through which bacterial communities exchange information and act in reaching a "quorum", which is the starting-point for decision-making: one of many different behavioral patterns will thereby be organised, such as biofilm organisation, bioluminescence, virulence or sporulation. Quorum-sensing includes not only chemotaxis, but also interpretation, which means that the incoming signs are measured against the background memory of the species- 
colony in their real life world. Interpretation before decision-making, coordination and organisation, such as fruiting body formation and cooperative hierarchical organisation, is context-dependent.

Bacteria, which in former times were viewed as lower life-forms, have now been recognised as masters of monitoring, computing, interpretation, coordination and organisation. Bacterial communicative competences are signmediated interactions between the same or related species, but also between non-related species according to different situational contexts (pragmatic level of analyses) and the coherent combinatorial patterns of signs according to the molecular syntax (syntactic level of analyses), both determining the content of the messages (semantic level of analyses), the meaning of sign-molecules for a bacterial community that shares a common background memory, and a competence for culture-dependent interpretation which is an advantage for adaptational purposes.

In addition, bacteria seem to have been a suitable habitat for the natural genome editing competences of persistent viruses throughout the entire history of life. Looking at their evolutionary roots opens the perspective on communalacting pre-cellular species which drove the evolution of cellular life.

\section{REFERENCES}

[1] Ben Jacob, E.; Levine, H. Self-engineering capabilities of bacteria. J. R. Soc. Interface, 2006; 3: 197-214.

[2] Bassler, B.L.; Losick, R. Bacterially Speaking. Cell, 2006; 125: 237-246.

[3] Hughes, D.T.; Sperandio, V. Inter-kingdom signalling: communication between bacteria and their hosts. Nat. Rev. Microbiol., 2008; 6: 111-120.

[4] Woese, C.; Kandler, O.; Wheelis, M. Towards a natural system of organisms: proposal for the domains Archaea, Bacteria, and Eucarya. Proc. Natl. Acad. Sci., 1990; 87: 4576-9.

[5] Pal, C.; Papp, B.; Lercher, M.J. Adaptive evolution of bacterial metabolic networks by horizontal gene transfer. Nat. Genet., 2005; 37: 1372-1375.

[6] Kaiser, D.; Losick, R. How and Why Bacteria talk to Each Other. Cell, 1993; 73: 873-885.

[7] Swift, S.; Bainton, N.J.; Winson, M.K. Gram-negative bacterial communication by $\mathrm{N}$-acyl homoserine lactones: a universal language? Trends Microbiol., 1994; 2: 193-198.

[8] Bassler, B.L. How bacteria talk to each other: Regulation of gene expression by quorum sensing. Curr. Opin. Microbial., 1999; 2: 582-587.

[9] Bassler, B.L. Small talk: cell-to-cell communication in bacteria. Cell, 2002; 109: 421-424.

[10] Schauder, S.; Bassler, B.L. The languages of bacteria. Genes Dev., 2001; 15: 1468-1480.

[11] Ben Jacob, E.; Becker, I.; Shapira Y, Levine H. Bacterial linguistic communication and social intelligence. Trends Microbiol., 2004; 12: 366-372.

[12] Schauder, S; Shokat, K; Surette, M.G; Bassler, B.L. The LuxS family of bacterial autoinducers: biosynthesis of a novel quorumsensing signal molecule. Mol. Microbiol., 2001; 41: 463-476.

[13] Crespi, B.J. The evolution of social behavior in microorganisms. Trends Ecol. Evol., 2001; 16: 178-183.

[14] Manefield, M; Turner, S.L. Quorum sensing in context: out of molecular biology and into microbial ecology. Microbiology, 2002; 148: 3762-3764.

[15] Greenberg, E.P. Bacterial communication: tiny teamwork. Nature, 2003; $424: 134$

[16] Daniels, R; Vanderleyden, J; Michiels, J. Quorum sensing and swarming migration in bacteria. FEMS Microbiol. Rev., 2004; 28 : 261-289.

[17] Waters, C.M; Bassler, B.L. Quorum sensing: cell to cell communication in bacteria. Annu. Rev. Cell Dev. Biol. 2005; 21: 319-346.
[18] Loh, J; Pierson, E.A; Pierson, L.S; Stacey, G; Chatteriee, A. Quorum sensing in plant associated bacteria. Curr. Opin. Plant Biol. 2002; 5 : 285-290.

[19] Konaklieva, M.I; Plotkin, B.J. Chemical communication - do we have a quorum? Mini Rev. Med. Chem., 2006; 6: 817-825.

[20] Davis, D.G; Parsek, M.R; Pearson, J.P; Iglewski, B.H; Costerton, J.W; Greenberg, E.P. The involvement of cell-to-cell signals in the development of a bacterial biofilm. Science, 1998; 280: 295-298.

[21] Fuqua, C; Greenberg, E.P. Listening in on bacteria: acylhomoserine lactone signalling. Nat. Rev. Mol. Cell Biol., 2002; 3: 685-695.

[22] Voloshin, S.A; Kaprelyants, A.S. Cell-cell interactions in bacterial populations. Biochemistry (mosc), 2004; 69: 1268-1275.

[23] Parsek, M.R; Greenberg, E.P. Sociomicrobiology: the connections between quorum sensing and biofilms. Trends Microbiol., 2005 13: 27-33.

[24] Ben Jacob E. Bacterial self-organization: co-enhancement of complexification and adaptability in a dynamic environment. Philos Transact A Math Phys. Eng. Sci., 2003; 361: 1283-1312.

[25] Witzany G. Serial Endosymbiotic Theory (SET): The biosemiotic update. Acta Biotheor., 2006; 54: 103-117.

[26] Witzany , G. The Logos of the Bios 2. Bio-communication. Helsinki: Umweb, 2007.

[27] Eigen, M; Winkler, R. Das Spiel - Naturgesetze steuern den Zufall. München: Pieper, 1975.

[28] Witzany G. From the ,Logic of the Molecular Syntax' to Molecular Pragmatism. Explanatory deficits in Manfred Eigen's concept of language and communication. Evol. Cogn., 1995; 1: 148-168.

[29] Witzany G. The Logos of the Bios 1. Contributions to the foundation of a three-leveled biosemiotics. Helsinki: Umweb, 2006.

[30] Camara, M; Williams, P; Hardman , A. Controlling infection by tuning in and tuning down the volume of bacterial small-talk. Lancet Infect. Dis., 2002; 2: 667-676.

[31] Wadhams, G.H; Armitage, J.P. Nat. Rev. Mol. Cell Biol., 2004; 5: 1024-1037.

[32] Stanley, N.R; Lazazzera, B.A. Environmental signals and regulatory pathways that influence biofilm formation. Mol. Microbiol., 2004; 52: 917-924.

[33] Wuertz, S; Okabe, S; Hausner, M. Microbial communities and their interactions in biofilm systems: an overview. Water Sci. Technol., 2004; 49: 327-336.

[34] Spoering, A.L.; Gilmore, M.S. Quorum sensing and DNA release in bacterial biofilms. Curr. Opin. Microbiol., 2006; 9: 133-137.

[35] Henke, J.M.; Bassler, B.L. Bacterial social engagements Trends Cell Biol., 2004; 14: 648-656.

[36] Sun, J; Daniel, R; Wagner-Dobler, I; Zeng, AP. Is autoinducer-2 a universal signal for interspecies communication: a comperative genomic and phylogenetic analysis of the synthesis and signal transduction pathways. BMC Evol. Biol., 2004; 4: 36.

[37] Shapiro JA. Thinking about bacterial populations as multicellular organisms. Annu. Rev. Microbiol., 1998; 52: 81-104.

[38] Visick, K.L; Fuqua C. Decoding Microbial Chatter: Cell-Cell Communication in Bacteria. J. Bacteriol., 2005; 187: 5507-5519.

[39] Lenz, D.H.; Mok, K.C.; Lilley, B.N.; Kulkarni, R.V.; Wingreen, N.S.; Bassler, B.L. The small RNA Chaperone Hfq and multiple small RNAs control quorum sensing in Vibrio harveyi and Vibrio Cholerae. Cell, 2004; 118: 69-82.

[40] Teplitski, M.; Robinson, J.B.; Bauer, W.D. Plants secrete substances that mimic bacterial $\mathrm{N}$ acylhomoserine lactone signal activities and affect population density dependent behaviors in associated bacteria. Mol. Plant Microbe. Interact., 2000; 13: 637-48.

[41] Vogel, J.; Sharma, C.M. How to find small non-coding RNAs in bacteria. J. Biol. Chem., 2005; 386: 1219-1238.

[42] Bauer, W.D; Robinson, J.B. Disruption of bacterial quorum sensing by other organisms. Curr. Opin. Biotechnol., 2002; 13: 234-237.

[43] Keller, L.; Surette, M.G. Communication in bacteria: an ecological and evolutionary perspective. Nat. Rev. Microbiol., 2006; 4: 249258.

[44] Fuqua, C; Winans, S.C.; Greenberg, E.P. Census and consensus in bacterial ecosystems: the LuxR-LuxI family of quorum-sensing transcriptional regulators. Annu. Rev. Microbiol., 1996; 50: 727751.

[45] Bais, H.P, Park, S.W.; Weir, T.L.; Callaway, R.M.; Vivanco, J.M. How plants communicate using the underground information superhighway. Trends Plant Sci., 2003; 9:26-32.

[46] Walker, T.S.; Bais, H.P.; Grotewold, E.; Vivanco, J.M. Root exudation and rhizosphere biology. Plant Physiol., 2003; 132: 44-51. 
[47] Hayashi, M. Plastid proteins crucial for symbiotic fungal and bacterial entry into plant roots. Nature, 2005; 433: 527-31.

[48] Samaj, J.; Baluska, F.; Voigt, B.; Schlicht, M.; Volkmann, D.; Menzel, D. Endcytosis, actin cytoskeleton, and signalling. Plant Physiol. 2004; 135: 1150-1161.

[49] Kiers, E.T.; Rousseau, R.A; West, S.A.; Denison , R.F. (2003). Host sanctions and the legume-Rhizobium mutualism. Nature, 2003; 425: 78-81.

[50] Sharma, A.; Sahgal, M.; Johri, B.N. Microbial communication in the rhizosphere: Operation of quorum sensing. Curr. Sci., 2003; 85: 1164-1172.

[51] Velicer, G.J. Social strife in the microbial world. Trends Microbiol., 2003; 11: 330-337.

[52] Rice, G.; Tang, L.; Stedman, K.; Roberto, F.; Spuhler, J.; Gillitzer, E.; Johnson, J.E.; Douglas, T.; Young, M. The structure of a thermophilic archaeal virus shows a double-stranded DNA viral capsid type that spans all domains of life. Proc. Natl. Acad. Sci., 2004; 101: 7716-7720.

[53] Sperandio, V.; Torres, A.G.; Jarvis, B.; Nataro, J.P.; Kaper, J.B. Bacteria-host communication: the language of hormones. Proc. Natl. Acad. Sci., 2003; 100: 8951-8956.

[54] Margulis, L. Archaeal-eubacterial mergers in the origin of Eukarya: Phylogenetic classification of life. Proc. Natl. Acad. Sci., 1996; 93: 1071-1076.

[55] Margulis L. Die andere Evolution. Heidelberg: Spektrum Akademischer Verlag, 1999.

[56] Margulis L. Serial endosymbiotic theory (SET) and composite individuality. Transition from bacterial to eukaryotic genomes. Microbiol. Today, 2004; 31: 173-174.

[57] Margulis, L.; Sagan, D. Acquiring Genomes. A Theory of the Origin of Species. New York: Basic Books, 2002.

[58] Witzany, G. Natural history of life: history of communication logics and dynamics. SEED J 2005; 5: 27-55.

[59] Batut, J.; Andersson, G.E.; O'Callaghan, D. The evolution of chronic infection strategies in the a-proteobacteria. Nat. Rev. Microbiol., 2004; 2: 933-945.

[60] Blech, J. Leben auf dem Menschen. Die Geschichte unserer Besiedler. Hamburg: Rowohlt Taschenbuch Verlag, 2000.

[61] Federle, M.J.; Bassler, B.L. Interspecies communication in bacteria. J. Clin. Invest., 2003; 112: 1291-1299.

[62] Dunn, A.K.; Handelsman, J. Toward an understanding of microbial communities through analysis of communication networks. Antonie van Leeuwenhoeck, 2002; 81: 565-574.

[63] Gray, K.M. Intercellular communication and group behavior in bacteria. Trends Microbiol., 1997; 5: 184-188.

[64] McNab, R.; Lamont, R.J. Microbial dinner-party conversations. The role of LuxS interspecies communication. J. Med. Microbiol., 2003; 52: 541-545.

[65] Velicer, G.J.; Kroos, L.; Lenski, R.E. Developmental cheating in the social bacterium Myxococcus Xanthus. Nature, 2000; 404: 598601.

[66] Shapiro JA. Bacteria are small but not stupid: cognition, natural genetic engineering and sociobacteriology. Stud Hist Philos Biol. Biomed. Sci., 2007; 38: 807-819.

[67] Velicer, G.J.; Yu, Y.T. Evolution and novel cooperative swarming in the bacterium Myxococcus Xanthus. Nature, 2003; 425: 75-78.

[68] Kreft, JU. Biofilms promote altruism. Microbiology, 2004; 150: 2751-2760.

[69] Taga, M.E.; Bassler, B.L. Chemical communication among bacteria. Proc. Natl. Acad. Sci., 2003; 100: 14549-14554.

[70] Wang, L.H.; He, Y.; Gao, Y.; Wu, J.E.; Dong, Y.H.; He, C.; Wang, S.X.; Weng , L.X.; Xu, J.L.; Tay, L.; Fang, R.X.; Zhang, L.H. A bacterial cell-cell communication signal with cross-kingdom structural analogues. Mol. Microbiol., 2004; 51: 903-912.

[71] Kaiser, D.; Welch, R. Dynamics of fruiting body morphogenesis. $J$. Bacteriol., 2004; 186: 919-927.

[72] Kolenbrander, P.E.; Andersen, R.N.; Blehert, D.S.; Egland, PG, Foster JS, Palmer RJ. Communication among Oral Bacteria. Microbiol. Mol. Biol. Rev., 2002; 66: 486-505.

[73] Kolenbrander, P.E.; Egland, P.G.; Diaz, P.I.; Palmer, R.J. Genomegenome interactions: bacterial communities in initial dental plaque. Trends Microbiol., 2005; 13: 11-15.

[74] Rickard, A.H.; Palmer, J.R.; Blehert, D.S.; Campagna, S.R.; Semmelhack, M.F.; Egland, P.G.; Bassler, B.L.; Kolenbrander, P.E. Autoinducer 2: a concentration-dependent signal for mutualistic bacterial biofilm growth. Mol. Microbiol., 2006; 60: 1446-1456.
[75] Sahasrabudhe, A.; Dewhirst, F.E. Bacterial diversity in human subgingival plaque. J. Bacteriol., 2001; 183: 3770-3783.

[76] Moore, W.E.C.; Moore, L.V.H. The bacteria of periodontal diseases. Periodontology 2000, 1994; 5: 66-77.

[77] Kroes, I.; Lepp, P.W.; Relman, D.A. Bacterial diversity within the human subgingival crevice. Proc. Natl. Acad. Sci., 1999; 96: 14547-14552.

[78] Paster, B.J.; Boches, S.K.; Galvin, J.L.; Ericson, R.E.; Lau, C.N.; Levanos, V.A.; Sahasrabudhe, A.; Dewhirst, F.E. Bacterial diversity in human subgingival plaque. J. Bacteriol., 2001; 183: 37703783.

[79] Imaizumi-Anraku, H.; Takedam N.; Cherpentierm, M.; Perry, J.; Miwa, H.; Umehara, Y.; Kouchi, H.; Murakami, Y.; Mulder, L.; Vickers, K.; Pike, J.; Downie, A.; Wang, T.; Sato, S.; Asamizu, M.; Tabata, S.; Yoshikawa, M.; Murooka, Y.; Wu, G.J.; Kawaguchi, M.; Kawasaki, S.; Parniske, M.; Hayashi, M. Plastid proteins crucial for symbiotic fungal and bacterial entry into plant roots. $\mathrm{Na}$ ture, 2005; 433: 527-531.

[80] Xie, G.; Bonner, C.A.; Song, J.; Keyhani, N.O.; Jensen, R.A. Intergenomic displacement via lateral gene transfer of bacterial trp operons in an overall context of vertical genealogy. MBC Biol., 2004; 2: 15 .

[81] Thomas, C.M.; Nielsen, K.M. Mechanisms of, and barriers to, horizontal gene transfer between bacteria. Nat. Rev. Microbiol., 2005; 3: 711-721.

[82] Bordenstein, S.R.; Reznikoff, W.S. Mobile DNA in obligate intracellular bacteria. Nat. Rev. Microbiol., 2005; 3: 688-699.

[83] Gogarten, J.P.; Townsend , J.P. Horizontal gene transfer, genome innovation and evolution. Nat. Rev. Microbiol., 2005; 3: 679-687.

[84] Jain, R.; Rivera, M.C.; Lake, J.A. Horizontal gene transfer among genomes: The complexity hypothesis. Proc. Natl. Acad. Sci., 1999; 96: 3801-3806.

[85] Jain, R.; Rivera, M.C.; Moore, J.E.; Lake, J.A. Horizontal Gene Transfer accelerates genome innovation and evolution. Mol. Biol. Evol., 2003; 20: 1598-1602.

[86] Brown, J.R. Ancient horizontal gene transfer. Nat. Rev. Genet., 2003; 4: 122-132.

[87] Solomon, J.M.; Grossman, A.D. Who's competent and when: regulation of natural genetic competence in bacteria. Trends Genet., 1996; 12 : 150-155.

[88] Berg, O.G.; Kurland, C.G. Evolution of Microbial Genomes: Sequence Acquisition and Loss. Mol. Biol. Evol., 2002; 19: 22652276.

[89] Rivera, M.C.; Lake, J.A. The ring of life provides evidence for a genome fusion origin of eukaryotes. Nature, 2004; 431: 152-155.

[90] Kunin, V.; Goldovsky, L.; Darzentas, N.; Ouzounis, C.A. The net of life: Reconstructing the microbial phylogenetic network. Gen. Res., 2005; 15: 954-959.

[91] Tettelin, H.; Masignani, V.; Cieslewicz, M.J.; Donati, C.; Medini, D.; Ward, N.L.; Angiuoli, S.V.; Crabtree, J.; Jones, A.L.; Durkin, A.S.; DeBoy, R.T.; Davidsen, T.M.; Mora, M.; Scarselli, M.; Ros, I.M.; Peterson, J.D.; Hauser, C.R.; Sundaram, J.P.; Nelson, W.C.; Madupu, R.; Brinkac, L.M.; Dodson, R.J.; Rosovitz, M.J.; Sullivan, S.A.; Daugherty, S.C.; Haft, D.H.; Selengut, J.; Gwinn, M.L.; Zhou, L.; Zafar, N.; Khouri, H.; Radune, D.; Dimitrov, G.; Watkins, K.; O'Connor, K.J.B.; Smith, S.; Utterback, T.R.; White, O.; Rubens, C.E.; Grandi, G.; Madoff, L.C.; Kasper, D.L.; Telford, J.L.; Wessels, M.R.; Rappuoli, R.; Fraser, C.M. Genome analysis of multiple pathogenic isolates of Streptococcus agalactiae: implications for the microbial "pan-genome". Proc. Natl. Acad. Sci., 2005; 102: 13950-13955.

[92] Villarreal, L.P. Viruses and the Evolution of Life. Washington: American Society for Microbiology Press, 2005.

[93] Graumann, P.L. Cytoskeletal elements in bacteria. Curr. Opin Microbiol., 2004; 7: 565-571.

[94] Graumann, P.L.; Defeu-Soufo, H.J. An intracellular actin motor in bacteria? Bioessays, 2004; 26: 1209-1216.

[95] Defeu-Soufo, J.H., Graumann, P.L. Dynamic movement of actinlike proteins within bacterial cells. EMBO Rep., 2004; 5: 789-794.

[96] Gitai, Z. The New Bacterial Cell Biolgy: Moving Parts and Subcellular Architecture. Cell, 2005; 120: 577-586.

[97] Guerrero, R.; Berlanga, M. The hidden side of the prokaryotic cell: rediscovering the microbial world. Int. Microbiol., 2007; 10: 157168.

[98] Witzany, G. Natural Genome-editing Competences of Viruses. Acta Biotheor., 2006; 54: 235-253. 
[99] Forterre, P. The origin of DNA genomes and DNA replication proteins. Curr. Opin. Microbiol., 2002; 5: 525-532.

[100] Forterre, P. The two ages of the RNA world, and the transition to the DNA world: a story of viruses and cells. Biochimie, 2005; 87: 793-803.

[101] Forterre, P. The origin of viruses and their possible roles in major evolutionary transitions. Virus Res., 2006; 117: 5-16.

[102] Villarreal, L.P.; DeFilippis, V.R. A hypothesis for DNA viruses as the origin of eukaryotic replication proteins. J. Virol., 2000; 74: 7079-7084.

[103] Villarreal, L.P. Can Viruses Make Us Humans? Proc. Am. Phil. Soc., 2004; 148: 296-323.

[104] Villarreal, L.P.; DeFilippis, V.R.; Gottlieb, K.A. Acute and Persistent Viral Life Strategies and Their Relationship to Emerging Diseases. Virology, 2000; 272: 1-6.

[105] Pandey, D.P.; Gerdes, K. Toxin-antitoxin loci are highly abundant in free-living but lost from host-associated prokaryotes. Nucleic Acids Res., 2005; 33: 966-976.

[106] Frost, L.S.; Leplae, R.; Summers, A.O.; Toussaint, A. Mobile genetic elements: the agents of open source evolution. Nat. Rev. Microbiol., 2005; 3: 722-32.

[107] Holmes, A.J.; Gillings, M.R.; Nield, B.S.; Mabutt, B.C.; Nevalainen, K.M.; Stokes, H.W. The gene cassette metagenome is a basic resource for bacterial genome evolution. Environ. Microbiol., 2003; 5 : 383-394.

[108] Chen, I.; Christie, P.J.; Dubnau, D. The Ins and Outs of DNA Transfer in Bacteria. Science, 2005; 310: 1456-1460.

[109] Ryan, F. Genomic creativity and natural selection: a modern synthesis. Biol. J. Linn. Soc., 2006; 88: 655-672.

[110] Hambly, E.; Suttle, C.A. The viriosphere, diversity, and genetic exchange within phage communities. Curr. Opin. Microbiol. 2005; 8: 444-450.

[111] Kulakauskas, S.; Lubys, A.; Ehrlich, S.D. DNA RestrictionModification Systems Mediate Plasmid Maintenance. J. Bacteriol., 1995; 177: 3451-3454.

[112] Villarreal, L.P. DNA Virus Contribution to Host Evolution. In: Domingo E, Webster RG, Holland JF. Eds. Origin and Evolution of Viruses. London: Academic Press, 1999: 301-420.

[113] Takemura, M. Poxviruses and the origin of the eukaryotic nucleus. J. Mol. Evol., 2001; 52: 419-425.

[114] Bell, J.L. Viral Eukaryogenesis: Was the Ancestor of the Nucleus a complex DNA virus? J. Mol. Evol., 2001; 53: 251-256.

[115] Bell, P.J.L. Sex and the eukaryotic cell cycle is consistent with a viral ancestry for the eukaryotic nucleus. J. Theor. Biol., 2006; 243 : 54-63.

[116] Nandhagopal, N.; Simpson, A.A.; Gurnon, J.R.; Yan, X.; Baker, T.S.; Graves, M.V.; Van, Etten, J.L.; Rossmann, M.G. The structure and evolution of the major capsid protein of a large, lipidcontaining DNA virus. Proc. Natl. Acad. Sci., 2002; 99: 1475814763.

[117] Rice, S.A.; Givskov, M.; Steinberg, P.; Kielleberg, S. Bacterial signals and antagonists: the interaction between bacteria and higher organisms. J. Mol. Microbiol. Biotechnol., 1999; 1: 23-31.

[118] Khayat, R.; Tang, L.; Larson, E.T.; Lawrence, C.M.; Young, M.; Johnson, J.E. Structure of an archaeal virus capsid protein reveals a common ancestry to eukaryotic and bacterial viruses. Proc. Natl. Acad. Sci., 2005; 102: 18944-18949.

[119] Flores, R.; Delgado, S.; Gas, M.E.; Carbonell, A.; Molina, D.; Gago, S.; De la Pena, M. Viroids: the minimal non-coding RNAs with autonomous replication. FEBS Lett., 2004; 567: 42-48.

[120] Chiang, C.C.; Kennell, J.C.; Wanner, LA.; Lambowitz, A.M. A Mitochondrial Retroplasmid Integrates into Mitochondrial DNA by a Novel Mechanism Involving the Synthesis of a Hybrid cDNA and Homologous Recombination. Mol. Cell Biol., 1994; 14: 6419-6432.

[121] Chiang, C.C.; Lambowitz, A.M. The Mauriceville Retroplasmid Reverse Transcriptase Initiates cDNA Synthesis De Novo at the 3' End of tRNAs. Mol. Cell Biol., 1997; 17: 4526-4535.
[122] Forterre, P.; Gribaldo, S.; Brochier, C. Luca: the last universal common ancestor. Med. Sci., (Paris) 2005; 21 : 860-865.

[123] Witzany, G. Life: The Communicative Structure. Norderstedt: Libri BoD, 2000.

[124] Vetsigian, K.; Woese, C.; Goldenfeld, N. Collective evolution and the genetic code. Proc. Natl. Acad. Sci. USA., 2006; 103: 1069610701.

[125] Villarreal, L. Origin of Group Identity. Viruses, Addiction and Cooperation. Springer 2008.

[126] Diener, T.O. Circular RNAs: Relics of precellular evolution? Proc. Natl. Acad. Sci., 1989; 86: 9370-9374.

[127] Diener TO. Viroids and viroid-like satellite RNAs: a phylogenetic analysis. Prog. Clin. Biol. Res., 1991; 364: 243-256.

[128] Diener, T.O. The viroid: big punch in a small package. Trends Microbiol., 1993; 1: 289-294.

[129] Diener, T.O. Origin and evolution of viroids and viroid-like satellite RNAs. Virus Genes, 1995; 11: 119-131.

[130] Wang, M.B.; Bian, X.Y.; Wu, L.M.; Liu, L.X.; Smith, N.A.; Isenegger, D.; Wu, R.M.; Masuta, C.; Vance, V.B.; Watson, J.M.; Rezaian, A.; Dennis, E.S.; Waterhouse, P.M. On the role of RNA silencing in the pathogenicity and evolution of viroids and viral satellites. Proc. Natl. Acad. Sci., 2004; 101: 3275-3280.

[131] Daros, J.A.; Elena, S.F.; Flores, R. Viroids: an Ariadne's thread into the RNA labyrinth. EMBO Rep., 2006; 7: 593-598.

[132] Itaya, A.; Zhong, X.; Bundschuh, R.; Qi, Y.; Wang, Y.; Takeda, R. Harris, A.R.; Molina, C.; Nelson, R.A.; Ding, B. A Structured Viroid RNA Serves as a Substrate for Dicer-Like Cleavage to Produce Biologically Active Small RNAs but Is Resistant to RNAInduced Silencing Complex-Mediated Degradation. J. Virol., 2007; 81: 2980-2994.

[133] Calvin, K.; Li, H. RNA-splicing endonuclease structure and function. Cell Mol. Life Sci., 2008; Doi: 10.1007/s00018-008-7393-y

[134] McClure, M.A. The complexities of genome analysis, the Retroid agent perspective. Bioinformatics, 2000; 16: 79-95.

[135] Birgisdottir, A.B.; Johansen, S.D. Reverse splicing of a mobile twin-ribozyme group I intron into the natural small subunit rRNA insertion site. Biochem. Soc. Trans., 2005; 33: 482-484.

[136] Bapteste, E.; Charlebois, R.L.; MacLeod, D.; Brochier, C. The two tempos of nuclear pore complex evolution: highly adapting proteins in an ancient frozen structure. Genome Biol., 2005; 6: R85.

[137] Penny D, Poole A. The nature of the last universal common ancestor. Curr. Opin. Genet. Dev., 1999; 9: 672-677.

[138] Poole, A.K.; Jeffares, D.D.; Penny, D. The path from the RNA world. J. Mol. Evol., 1998; 46: 1-17.

[139] Poole, A.; Jeffares, D.; Penny, D. Early evolution: prokaryotes, the new kids on the block. BioEssays, 1999; 21: 880-889.

[140] Witzany, G. Telomeres in Evolution and Development from Biosemiotic Perspective. Nat. Prec. 2007; doi:10.1038/npre.2007. 932.2

[141] Masse, E.; Gottesman, S. A small RNA regulates the expression of genes involved in iron metabolism in Escherichia coli. Proc. Natl. Acad. Sci., 2002; 99: 4620-4625.

[142] Wassarman, K.M. Small RNAs in Bacteria: Diverse Regulators of Gene Expression in Response to Environmental Changes. Cell, 2002; 109: 141-144.

[143] Majdalani, N.; Vanderpool, C.K.; Gottesman, S. Bacterial Small RNA Regulators. Crit. Rev. Biochem. Mol. Biol., 2005; 40: 93-113.

[144] Tu, K.C.; Bassler, B.L. Multiple small RNAs act additively to integrate sensory information and control quorum sensing in Vibrio harveyi. Genes Dev., 2007; 21: 221-233.

[145] Hammer, B.K. Bassler BL. Regulatory small RNAs circumvent the conventional quorum sensing pathway in pandemic Vibrio cholerae. Proc. Natl. Acad. Sci., 2007; 104: 11145-11149.

[146] Jeffares, D.C.; Poole, A.M.; Penny, D. Relics from the RNA World. J. Mol. Evol., 1998; 46: 18-36. 